\title{
Perception of Academics of Medicine of the Basic Cycle on the Importance of the Teaching of Human Anatomy for the Clinical Cycle
}

Façanha Barreto $\mathrm{JE}^{1,3}$, Freitas Filho $\mathrm{JE}^{3 *}$, de Lima Costa $\mathrm{PJ}^{3}$, Gonçalves RC ${ }^{3}$, Marcelo Kervin Reis Frota ${ }^{3}$, Costa Gonçalves S 3 , Sousa Ayres de Moura JR³ , Souza Sanders JV2, de Paula Uchôa $\mathrm{FE}^{2}$, Barros Cavalcante J², Bezerra Cavalcanti ${ }^{4}$, de Lucena JD1, de Souza HN5 , Binda Pimenta $\mathrm{H}^{1}$ and Santos Cerqueira $\mathrm{G}^{1,3}$

${ }^{1}$ Post-Graduate Program in Morphofunctional Sciences, Federal University of Ceara, Fortaleza, Ceara, Brazil

${ }^{2}$ Academic League of Anatomy and Surgery, Department of Morphology, Faculty of Medicine Federal University of Ceará, Fortaleza, Ceara, Brazil

${ }^{3}$ Anatomy Monitoring Program, Department of Morphology, Faculty of Medicine, Federal University of Ceará, Fortaleza, Ceará, Brazil

${ }^{4}$ Anatomy Teacher, Federal University of Piauí, Brazil

${ }^{5}$ Research Group on Education, Law and Health, Brazil

*Corresponding author: José Elício Freitas Filho, Department of Morphology - Federal University of Ceara Rua Delmiro de Farias, s/n - Campus Porangabussu/CE, CEP: 60.430-170, Brazil, Tel: +55 (85) 3366-8497; Email: giufarmacia@hotmail.com

\section{Abstract}

The Human Anatomy is a discipline of vital importance for medical training, but each year the time load of this discipline has been reduced implying in the learning of it. Thus the objective of this work is to investigate the perception of medical students of the basic cycle on the importance of teaching anatomy to the clinical cycle. An analytical study was carried out randomly through the application of online forms with a structured questionnaire. The sample consisted of 51 volunteers from both groups. It has been found that most students have a good affinity with Human Anatomy and 53\% consider that the degree of their anatomical knowledge on a scale of "0" to "10" is between "7" (37.3\%) and "8" (15.7\%). Regarding the importance of this knowledge for a good performance in the clinical cycle, $90.2 \%$ answered that they considered "very important" (74.5\%) or "extremely important" (15.7\%). The fifth question, which asked whether they considered their bases in anatomy enough to perform well in the clinical cycle, added up to $43.1 \%$ of students who considered them to be 
insufficient. It was observed that $58.8 \%$ of the interviewees considered the anatomical revision at the beginning of the clinical cycle to be of vital importance. Finally, participants were asked to select up to two methodologies that were best for the possible revision activity, with the most chosen being: "digital flashcards" and "theoretical-practical classes", both developed by the anatomy monitors. It was found that students consider anatomical knowledge essential for good performance in the clinical cycle. Therefore, the implementation of a human anatomy review activity at the beginning of the 5th semester should be encouraged, using the students' preferred methodologies.

Keywords: Anatomy; Education; Medicine; Morphology; Teaching

\section{Introduction}

Human Anatomy is one of the oldest medical sciences, studying morphological structures and functions of the human body [1]. Anatomy is a fundamental and sustaining column for medical teaching, since its understanding is required to for good clinical practice [2].

At present anatomy is taught at the beginning of the medical course or preclinical cycle and many of its knowledge are lost during the clinical cycle due to lack of use or due to mechanical learning, thus occurring a disconnection with basic cycle with clinical cycle.

Establishing a strong link early on between preclinical coursework and the clinical context is necessary for students to be able to recognize the practical relevance of the curriculum during their preclinical anatomical courses and to transfer knowledge more easily [3].

A strict separation of basic and clinical sciences is inadequate under current conditions, where students need to process more and more information in less time [4]. Students quickly forget most of the information as long as they do not see the facts applied to clinical problems [5]. Therefore, a practical training base would be more appropriate with the use of effective teaching methods.

Regarding teaching methodology, until the beginning of the new millennium, medical education (of which anatomy is an important pillar during the first year of the career) has been carried out in the traditional teachercentered and delivery-based way information of an isolated disciplinary knowledge. In this model, the subject is located within a rigid curriculum loop, where learning is achieved through the opportunity to study a specific subject available [6]. Thus the introduction of active methodologies with real clinical cases would facilitate the integration of the basic with clinical.
Although there are several classic anatomical studies, few studies show the relationship between basic and clinical education, especially where mechanical and traditional learning is stimulated. Thus, objective of this work is to investigate the perception of medical students of the basic cycle on the importance of teaching anatomy to the clinical cycle.

\section{Methodology}

A cross - sectional study with a quantitative approach was carried out with academics of the Medicine Course of a Higher Education Institution (IES) of Ceará.

The study was carried out in a reference higher education institution in Medicine teaching in Ceará Brazil.

The criterion used to select the students was with an active university enrollment, being over 18 years old and studying in the morphology department. The sample consisted of 38 students, selected through randomized stratified sampling. Similar criteria to studies of Tosteson DC [5].

The instrument used for data collection was a structured questionnaire, containing easy-to-understand questions. For the application of the questionnaire were selected and trained two academics of the Medicine Course, who applied the questionnaires during the classroom anatomy practices. There were applied online forms composed of structured questions applied to 51 volunteers of the two groups of the basic cycle of clinical cycle.

For the individual interview, prior written consent was obtained from all study participants. Selected and trained students under the supervision of a teacher performed data collection. Prior to application, 
individuals were instructed on the voluntary nature of the study and were granted confidentiality by anonymity. A free and informed consent form was presented to each participant in accordance with Resolution 466/12 [6]. It was used to organize the database computer program "Excel" version 2010. This study was conducted in accordance with the principles of the Declaration of Helsinki.

\section{Results and Discussion}

When students were asked about how much they like studying Anatomy, an amount of $9.8 \%$ said that they like studying Anatomy very much. Besides this, a total of $37.3 \%$ classified as "Average" and another $37.39 \%$ as "Not too much" their affinity to study this science. And, $9.8 \%$ of students said that they like study Anatomy just "A little" and other $5.9 \%$ said that do not like studying even a little.

\begin{tabular}{|c|c|}
\hline Category & \% \\
\hline Very much & $9.80 \%$ \\
\hline Avarage & $37.30 \%$ \\
\hline Not too much & $37.39 \%$ \\
\hline A little & $9.80 \%$ \\
\hline Not even a little & $5.90 \%$ \\
\hline
\end{tabular}

Table 1: How much students like studying anatomy?

\begin{tabular}{|c|c|c|c|}
\hline Category & $\mathbf{n}$ & $\mathbf{\%}$ & Média $\mathbf{E P P M}$ \\
\hline Grade 2 & 4 & $7.69 \%$ & \\
\hline Grade 3 & 1 & $1.92 \%$ & \\
\hline Grade 4 & 4 & $7.69 \%$ & \\
\hline Grade 5 & 6 & $11.53 \%$ & \\
\hline Grade 6 & 10 & $19.23 \%$ & \\
\hline Grade 7 & 19 & $36.53 \%$ & $6,03 \pm 0,2346$ \\
\hline Grade 8 & 8 & $15.38 \%$ & \\
\hline
\end{tabular}

Table 2: How do students qualify their knowledge of Anatomy on a scale from 1 to 10 at the end of the basic cycle?

About the grade that students used to qualify their knowledge of Anatomy, $7.69 \%$ classified as grade 2, 1.92 $\%$ classified as grade 3, $7.69 \%$ classified as grade 4 . Moreover, $11.53 \%$ classified their proficiency in Anatomy as grade $5,19.23 \%$ as grade $6,36.53 \%$ as grade 7 and
$15.38 \%$ as grade 8 . Finally, no students classified themselves as grade 1, not even 9 or 10 .

\begin{tabular}{|c|c|}
\hline Category & $\mathbf{\%}$ \\
\hline Extremely important & $15.70 \%$ \\
\hline Very important & $74.50 \%$ \\
\hline Not too much or not too little & $7.80 \%$ \\
\hline Litlle important & $2 \%$ \\
\hline
\end{tabular}

Table 3: Importance of anatomy for the clinical cycle.

When students were asked about how much they find Anatomy important to have a good proficiency in Clinical Cycle, $15.7 \%$ found it extremely important and $74.5 \%$ found it very important. Although, $7.8 \%$ think that Anatomy is not too much or not too little important and $2 \%$ find it little important.

\begin{tabular}{|c|c|c|}
\hline Category & $\mathbf{n}$ & $\mathbf{\%}$ \\
\hline Enough & & $56.90 \%$ \\
\hline Insufficient & & $43.10 \%$ \\
\hline
\end{tabular}

Table 4: The students' perception of their own anatomical knowledge to perform well in the Clinical Cycle.

When students were asked if their knowledge of Anatomy is enough to have a good proficiency in clinical cycle, an amount of $56.9 \%$ found their knowledge "Enough", but a total of $43.1 \%$ evaluated their knowledge as "Insufficient".

\begin{tabular}{|c|c|c|}
\hline Category & n & \% \\
\hline Extremely needed & & $13.70 \%$ \\
\hline Very needed & & $58.80 \%$ \\
\hline Not much or not little needed & & $19.60 \%$ \\
\hline Little needed & & $7.80 \%$ \\
\hline
\end{tabular}

Table 5: How important is it for students to review Anatomy at the beginning of each module during the Clinical Cycle?

About how important students think that would be good if there was a review of anatomy before each clinical module, $13.7 \%$ found it extremely needed and $58.8 \%$ find it very needed. In the other hand, $19.6 \%$ and $7.8 \%$ found it "Not much or not little needed" and "Little needed", respectively. 


\begin{tabular}{|c|c|c|}
\hline Category & $\mathbf{n}$ & $\mathbf{\%}$ \\
\hline Theoretical classes & 6 & $6.31 \%$ \\
\hline Theoretical-practical classes & 29 & $30.52 \%$ \\
\hline Digital flashcards & 30 & $31.57 \%$ \\
\hline Questions Databases & 17 & $17.89 \%$ \\
\hline Summary & 12 & $12.63 \%$ \\
\hline No preference & 1 & $1.05 \%$ \\
\hline
\end{tabular}

Table 6: What kind of methodology would students prefer during these review moments during the Clinical Cycle?

When students were asked about which methodology they would prefer in these reviewing moments, 6.31\% preferred "Theoretical classes" and 30.52\% preferred "Theoretical-practical classes". Besides this, $31.57 \%$ think that "Digital flashcards" and $17.89 \%$ think that "Questions Databases "would be a good way to review Anatomy. Moreover, $12.63 \%$ would like to review by summaries, and $1.05 \%$ has no preference about the methodology.

\section{Discussion}

In Brazil, over the last four years, several courses of medicine were opened by a policy that is unbridled and deliberated by the Ministry of Education, which decreases the quality of teaching anatomy in the capital and especially in the interior. In addition, teaching practices were compromised by the inadequate use of teaching methodologies and active lack of corpses for all institutions of higher education in the interior of State [7].

In addition, there are a large number of teachers without adequate teacher training and with difficulty integrating basic education into clinical teaching due to lack of clinical experience, i.e. the famous teachers with only academic training without clinical experience of their profession. This ends up intervening in the clinical extrapolation of the student and sometimes making the classes demotivating because they do not demonstrate the clinical importance of the anatomical structure.

The evolution in undergraduate medical school curricula has significantly impacted anatomy education. Although some areas of patient management differ in relevancy to anatomical education, there are areas of clinical care which were uniformly ranked as relying heavily on anatomical knowledge (imaging and diagnostic studies, physical examination, and arrival at correct diagnosis) by a variety of clinical specialists [8].

Publications in a variety of journals have described the problem of medical students' decreasing anatomical knowledge. Interestingly, the number of people making this assertion is growing, despite the lack of empirical evidence that today's medical graduates actually know less about anatomy than medical students in the past [9]. Nevertheless, many people are claiming that students' anatomical knowledge is impaired due to negative effects from several factors, including teaching by non-medically qualified teachers, diminished use of cadaver dissection as a teaching tool and neglect of vertical integration of anatomy teaching [9].

In our studies it was not possible to really identify whether the student likes or dislikes anatomy, because the opinions have been divided, but most have stated that they like anatomy. We believe that the traditional teaching with absence of active methodologies lead the student to perform mechanical learning and not to show pleasure in studying anatomy, except the students who enter the course thinking about being a surgeon and dedicate themselves more to anatomy.

In studies conducted with Indian students the researchers verified that it was found that the mean score is higher in the introduction of early clinical exposure and field of e-learning. Vertical integration is not well received by students [10].

Incorporating newer teaching aids over traditional one in Anatomy has been challenging both for the teachers and the learners. Different educational strategies are being used for teaching of Anatomy.

Even as advent of various technologies the use of corpse becomes essential to promote meaningful learning for students. Thus, cadaver donation programs are an important tool for anatomical study [10].

Human bodies are essential for teaching and research in health. The use of human cadavers, even if only for the demonstration of anatomical structures, was considered indispensable for the teaching-learning process of human anatomy [11].

Furthermore, there is a remarkable opportunity for clinical and preclinical educators to collaborate in the training of young academics. Both sides can benefit from this interaction and collaboratively provide an adequate, optimal and sustainable outcome [12]. Thus the early introduction of clinical anatomy can aid in the process of teaching and learning anatomy with regard to the learning methods, the students interviewed prefer the teaching through Digital flashcards and practical classes 
associated with theories. A study by Jaiswal Rashmi, et al. in Bhopal showed that $54.26 \%$ students preferred multimedia teaching methods to a better anatomy teaching methodology and it relies on scientific and does not cause lack of attention [13].

Researcher from India shows the different teaching strategies used during theoretical classes while teaching gross anatomy important for acquiring knowledge among them method of teaching chalk and frame, plasticines and LCD projector [10].

In studies carried out in the Brazilian Northeast, the authors verified that most of the classes were carried out with Classes with plastic mannequin and in the form of seminar [7]. These practices make learning difficult and do not adequately bridge the basic cycle with the clinical cycle.

We found that students know the importance of the anatomy of the basic cycle for the clinical cycle, but many knowledge is lost by the lack of integration of the basic course with cynical cycle that starts only a year later. In this way a curricular reform would be an alternative to promote the integration of the basic cycle with the clinical cycle, since there would be revisions and review to the anatomical knowledge. In addition, anatomical revisions before the start of each module of the clinical cycle would promote further meaningful learning [14].

\section{Acknowledgements}

The authors wish to thank the students that participated in this study and UFC.

\section{References}

1. Mompeo B, Perez P (2003) Relevance of Gross Human Anatomy in health primary care and in clinical disciplines of medical studies. Educ med 6(2).

2. Salbego C, Elaine MDO, Márcia ARS, Paula RB (2015) Percepções Acadêmicas sobre o Ensino e a Aprendizagem em Anatomia Humana. Rio de Janeiro 39(1): 23-31.

3. Rafai N, Lemos M, Hawari A, Gerhardt Szép S, Classen Link I, et al. (2016) Anatomy meets dentistry! Linking anatomy and clinical practice in the preclinical dental curriculum. BMC Med Edu 16(1): 305.
4. Metcalf NF (1982) Modelos de grupo de pares em instrução de exame como parte integrante da anatomia macroscópica médica.J Edu Med 57: 640644.

5. Tosteson DC (1990) Novas vias na educação médica geral . New England Journal of Medicine 322: 234-238.

6. Barreto JEF, Sanders JVS, Brito HM, Collyer MC, Paula Uchôa FE, et al. (2018) Perception of Medical Students in the Front of an Active Evaluation Model of Cardiovascular Anatomy. SM J Clin Anat 2(3): 1016.

7. Brasil (2012) Ministério da Saúde. Conselho Nacional de Saúde. Comissão de Ética em Pesquisa em Seres Humanos. Diretrizes e Normas Regulamentadoras Envolvendo Seres Humanos. Brasília: Ministério da Saúde.

8. Oliveira PS, Jalles DL, Francisco ROS, Katarina MBL, Jonas NFM, et al. (2017) The Teaching Of Human Anatomy In Brazil: The Reality Of Northeast Brazil. Int J Anat Res 5(4.2): 4623-4629.

9. Lazarus MD, Chinchilli VM, Leong SL, Kauffman, Gordon L Jr (2012) Perceptions of Anatomy: Critical Components in the Clinical Setting. Anat Sci Edu 5(4): 187-199.

10. Bergman EM, Van Der Vleuten CP, Scherpbier AJ (2011) Why don't they know enough about anatomy? A narrative review. Med Teach 33(5): 403409.

11. Bandyopadhyay R, Biswas R (2017) Students' Perception and Attitude on Methods of Anatomy Teaching in a Medical College of West Bengal, India. J Clin Diagn Res 11(9): AC10-AC14.

12. Costa-Sobrinho OP, Santos CG, Lucena JD, Oliveira FR, Brasileiro LKM, et al. (2018) Body Donation Program for Anatomical Teaching: The Perception of Brazilian Students. J Hum Anat 2(2): 000125.

13. André K, Ingo B, Christine F, Kay-Rüdiger K, Thomas B, et al. (2018) Implementation of clinical references for undergraduates in anatomy Annals of Anatomy.

14. Jaiswal R, Sathe S, Gajbhiye V, Sathe R (2015) Students perception on methods of anatomy teaching and assessment. Int J Anat Res 3(2): 1103-1108.

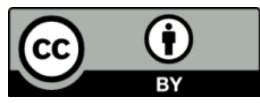

Freitas Filho JE, et al. Perception of Academics of Medicine of the Basic Cycle on the Importance of the Teaching of Human Anatomy for the Clinical Cycle. J Human Anat 2018, 2(3): 000134. 